\title{
EFFECTS OF AGMATINE ON ACOUSTIC STARTLE REFLEX AND AUDITORY SYSTEM IN RATS
}

\author{
Özlem Saatci ${ }^{1}$, Burcu Çevreli ${ }^{2}$, Tayfun Uzbay ${ }^{2}$ \\ Correspondence: oreleos@ hotmail.com \\ ${ }^{1}$ Health Sciences Univerty, Sancaktepe Traing and Education Hospital, Istanbul, Turkey \\ ${ }^{2} \ddot{U}$ sküdar University-Neuropsychopharmacology Application and Research Center, Istanbul, Turkey
}

\author{
Article History: \\ Received: October 7, 2020 \\ Accepted: April 21, 2021 \\ Published: July 1, 2021

\section{Cite this as:} \\ Saatci O, Çevreli B, Uzbay $T$. \\ Effects of agmatine on acoustic \\ startle reflex and auditory system \\ in rats. Malang Neurology \\ Journal; 2021.7:85-92. \\ http://dx.doi.org/10.21776/ub.mnj \\ .2021.007.02.1
}

\section{ABSTRACT}

Background: A polyamine, agmatine, has been proposed as a new neurotransmitter in the brain. Objective: The aim of this study was to evaluate the effects of acute and chronic agmatine treatment on the rat auditory system.

Methods: Male Wistar albino rats weighing between 280-330 grams were used. Animals were divided into four groups $(\mathrm{n}=8$ for each group). Acute and chronic agmatine $(160 \mathrm{mg} / \mathrm{kg}$ ) was administered to rats. Prepulse inhibition (PPI) of the acoustic startle reflex (ASR), distortion product otoacoustic emissions (DPOAEs), auditory brainstem responses (ABR) were evaluated in all groups.

Results: Both acute and chronic agmatine treatments also significantly disrupted PPI. Chronic but not acute treatment with agmatine produced some DPOAE and ABR changes in rats.

Conclusion: Our results suggested that chronic agmatine treatment for seven days resulted in some significant negative changes in cochlear function. Because the PPI of the ASR is also used as an indicator for psychoses, such as schizophrenia, in human and experimental animal studies, our findings also imply that the DPOAE and ABR tests may also be considered in the diagnosis and follow-up of patients with psychoses.

Keywords: Agmatine; Auditory brainstem responses; Distortion product otoacoustic emissions; Prepulse inhibition; Rat

\section{Introduction}

A polyamine, agmatine, has been proposed as a new neurotransmitter in the brain. Agmatine is synthesized in the brain, stored in the synaptic vesicles of neurons and secreted by $\mathrm{Ca} 2+-$ dependent depolarization. Agmatine also binds to alpha 2-adrenergic and imidazoline receptors, blocks N-methyl-D-aspartate (NMDA) receptors and other ligand-gated ion channels, and inhibits the enzyme nitric oxide synthase (NOS). ${ }^{1}$ In our previous study, we observed that agmatine $(160 \mathrm{mg} / \mathrm{kg}$, i.p) disrupted PPI of the acoustic startle reflex in rats. ${ }^{2}$ Because the disruption of PPI is a valid experimental ${ }^{3}$ and clinical ${ }^{4}$ test in schizophrenia and psychosis, this observation made us think there might be a relationship between agmatine and schizophrenia. The following studies supported this hypothesis. Thus, while Uzbay et al. ${ }^{5}$ showed significant increases in plasma agmatine levels in patients with schizophrenia, in a postmortem study, Liu et al. ${ }^{6}$ found increased agmatine concentrations in schizophrenia cases.

Polyamines (i.e., ornithine, putrescine, spermine and spermidine) are biogenic amines that are necessary for cellular functions ranging from DNA stabilization and gene expression regulation to ion channel function and, particularly, cell proliferation. Polyamines play a critical role in quickly dividing cells, such as those in the immune system and digestive tract. ${ }^{7}$ The polyamine stress response and polyamine stress-induced mental disorders such as schizophrenia have also been defined. ${ }^{8}$

ASR and PPI are used to characterize the physiological and anatomical properties of the sensory cortex, brain stem, and pontine nerve circuits, as well as to obtain information on drug effects. ${ }^{9}$ In addition, PPI of the ASR can be used to demonstrate behavioral reflections of a cochlear injury due to ototoxic drugs ${ }^{10}$ and to detect transient threshold shifts due to pure tone acoustic stimulation. ${ }^{11}$ Notably, the incidence of schizophrenia was also found to be higher in patients diagnosed with severe hearing loss. ${ }^{12}$ Another study on the frequency of hearing loss in patients with psychotic disorders failed to find a significant association between hearing loss and psychotic disorder; however, it noted a significant increase in the hearing thresholds of schizophrenia patients, which could promote hearing difficulties in noisy environments. ${ }^{13}$ The difficulties experienced by patients with schizophrenia in noisy environments may be related to both hearing loss and disturbances in sensory filtering mechanisms. Sensory filtering allows the regulation of the amount of sensory input to the brain. In patients with schizophrenia, there is insufficient filtering of secondary stimuli associated with significant sensory inputs due to sensory filtering disturbances. ${ }^{14}$

Alpha-difluoromethylornithine (DFMO), an irreversible inhibitor of ornithine decarboxylase (ODC) in the polyamine synthesis pathway and a potential antineoplastic 
drug, was observed to lead to reversible sensorineural hearing loss during phase II clinical trials. ${ }^{15}$ Subsequent studies confirmed DFMO-induced ototoxicity and indicated that polyamines may have some harmful effects in hearing systems. ${ }^{16,17}$ Agmatine, a polyamine that disrupts PPI, may also have toxic effects on hearing-related systems. However, the effects of agmatine on the hearing system have not been the subject of any study to date, which is important because agmatine is safely and widely used as a food supplement because it is believed to have some beneficial effects.

Thus, this study was conducted to evaluate the effects of acute and chronic agmatine treatment on the rat auditory system by measuring DPOAEs and ABRs.

\section{Methods}

\section{Animal and Laboratory Characteristics}

Thirty-two ten-week-old adult male Wistar albino rats weighing between 280-330 grams were included in this study. The animals were obtained from the Usküdar University Experimental Research Unit. All experiments were conducted according to the ethics rules indicated by the Helsinki Declaration and the Guide for the Care and Use of Laboratory Animals. This study was approved by the Usküdar University Ethical Committee of Animal Care, 22 January 2016, 2016/01.The rats were kept in a laboratory appropriate for a circadian rhythm of 12 hours of night/day (light from 7.00 a.m. to 7.00 p.m.) at room temperature $\left(22 \pm 3{ }^{\circ} \mathrm{C}\right)$ and a humidity of $60 \pm 5 \%$; the ambient noise level was less than $50 \mathrm{~dB}$. Four rats were housed per plexiglass cage. The rats were provided with food and water ad libitum, and standard care was given. All experiments were performed at the same time of day during the light period (09:00 a.m-11:30 a.m.). The research was conducted at the Neuropsychopharmacology Application and Research Center of Üsküdar University.

\section{Drugs}

Agmatine sulfate was obtained from Sigma-Aldrich Co. (St. Louise, Missouri, USA). Agmatine was dissolved in a physiologic saline solution and injected intraperitoneally in a volume of $1 \mathrm{~mL} / \mathrm{kg}$. The control animals received saline.

\section{Experimental Procedures}

\section{Prepulse inhibition of the acoustic startle reflex test}

Prepulse inhibition of the acoustic startle reflex was measured using Animal Acoustic Startle Reflex System chambers (SR-LAB, San Diego Instruments, San Diego, CA, USA) as described previously. ${ }^{2}$

Each test device consists of a soundproof, lighted, and ventilated chamber. Inside the chamber, there is an animal enclosure consisting of a plexiglass cylinder $(8.8 \mathrm{~cm}$ in diameter, $25 \mathrm{~cm}$ in length) in which the animal is placed during the experiment. The platform-mounted piezoelectric accelerometer under this cylinder transduces animal movements and startle responses digitized (0-4095), rectified, and recorded as 1001 -ms readings, starting at the onset of each startle stimulus. ${ }^{18}$ The average of these 100 readings was taken as the dependent measure. Background noise and acoustic stimuli were generated via a loudspeaker mounted $24 \mathrm{~cm}$ above the cylinder, and the background noise level was $70 \mathrm{~dB}[\mathrm{~A}]$ sound pressure level (SPL) during the study. SR-LAB software controlled the delivery of all stimuli to the animals and recorded the response. Calibration procedures were performed periodically for loudspeaker performance and stabilizer sensitivity.

The animals were handled for 5 minutes daily for three days before the PPI test. The next day, rats were habituated to the animal holders of the startle test system for 15 minutes without background noise or pulses. On the next day, the basal prepulse measurements were taken from the rats, without any drugs and injections, in the same way as the actual experimental procedure.

On the test day, the drug was administered, and the rats were placed in a startle chamber for a 5-min acclimatization period with $70 \mathrm{~dB}$ background noise, followed by five consecutive startle pulse-alone trials. This procedure was followed by 10 blocks of four trial types in a pseudorandomized order, and no two consecutive trials were identical. The trial types were as follows: I) pulsealone stimulus $(120 \mathrm{~dB})$; II) prepulse $(74 \mathrm{~dB})+$ pulse stimulus $(120 \mathrm{~dB})$; III) prepulse $(78 \mathrm{~dB})+$ pulse stimulus $(120 \mathrm{~dB})$; and IV) prepulse $(86 \mathrm{~dB})+$ pulse stimulus $(120$ $\mathrm{dB})$.

The pulse-alone stimulus was broadband noise at 120 $\mathrm{dB}[\mathrm{A}]$. The SPL lasted for $40 \mathrm{~ms}$, and all three prepulse stimuli were tone stimuli at a frequency of $3 \mathrm{kHz}$ for $20 \mathrm{~ms}$. The prepulse stimulus was applied $100 \mathrm{~ms}$ prior to pulse stimuli (onset to onset). Prepulse stimuli levels were selected at intensities that did not elicit a significant startle reflex when applied alone. The intertrial interval averaged $7.5 \mathrm{~s}$ ( $\min 3 \mathrm{~s}$; $\max 12 \mathrm{~s}$ ), including the no-stimulus trials (average of $15 \mathrm{~s}$ between the trials with a stimulus). The protocol lasted approximately $34 \mathrm{~min}$. There was a oneweek period between the initial measurements and test measurements, and then the same protocol was applied. The startle reflex was recorded as the average amplitude. PPI was defined as the percent reduction in amplitude of the startle reflex in the presence of the prepulse stimulus, and each of the three different prepulse intensities was calculated using the following formula:

PPI $\%=100-($ The mean of the startle reflex in trials with a prepulse $\mathrm{x} 100 /$ The mean of the startle reflex in trials without a prepulse),

\section{Hearing Assessments}

\section{Distortion Product Otoacoustic Emission Measurement}

DPOAE measurements were conducted with a CapellaMadsen (GN Otometrics A/S Taastrup, Denmark) device by using an appropriate newborn probe. This device was calibrated before each measurement. Measurements were performed in a silent room. The DPOAE test was applied to both ears of all rats. The f2/f1 ratio was fixed to 1.22 , and the L1-L2 difference was kept at $10 \mathrm{~dB}$ SPL (L1=70 dB SPL; L2=60 dB SPL). The DPOAEs were evaluated at tones equal to $2 \mathrm{f} 1-\mathrm{f} 2$ and generated at the frequencies corresponding to the geometric mean of $\mathrm{f} 1$ and $\mathrm{f} 2$. Signalto-noise ratio (SNR) values, which were calculated by subtracting the background noise level from the DPOAE measurements in $\mathrm{dB}$, were recorded at 2000, 3000, 4000, 6000 , and $8000 \mathrm{~Hz}$. SNR values of $3 \mathrm{~dB}$ or above were regarded as positive and used in evaluating the DPOAE results. 


\section{Auditory Brainstem Response Measurements}

ABR test was performed for both ears of each animal by using ICS Chartr EP 200 (Otometrics, Taastrup, Denmark). After the animals were anesthetized, subdermal electrodes were placed at the vertex (active electrode), over the mastoid bone of the tested ear (reference electrode) and over the contralateral mastoid bone (grounding electrode). A click stimulus was used as auditory stimuli within the bandpass filter, a range of $100-3000 \mathrm{~Hz}$ and a repetition rate of $21 \mathrm{~s}$ was set as filtering. The stimuli started at $80 \mathrm{~dB}$ and decreased by $10 \mathrm{~dB}$ for suprathreshold levels and by $5 \mathrm{~dB}$ for levels near the threshold. The thresholds were tested twice, and reproducibility was observed. The ABR threshold was defined as the lowest stimulus intensity at which wave II could be identified.

\section{Test Procedures}

The entire procedure is based on two experiments that measure the acute and chronic effects of agmatine. Each experiment consisted of two groups: a control group $(n=8)$ and a test group $(n=8)$. The rats with a baseline startle reflex of less than $20 \mathrm{~g}$ were not included in the study and were replaced with other rats that had a startle reflex above the desired threshold (this situation occurred only four times throughout the study). According to the baseline average PPI responses, those with low, medium, and high PPI responses were distributed equally in each group.

Animals were weighed prior to each PPI measurement, and no weight change was observed in any animals. DPOAE and ABR tests were performed in both ears under anesthesia, and before the tests, all rats were evaluated with an otoscope, and ears with plugs were cleaned and controlled for a normal external ear canal with an intact tympanic membrane. All animals demonstrated a normal otoscopic examination in the study. Rats were anesthetized with isoflurane. Isoflurane was administered to the rats in an induction chamber with a vaporizer at $4 \%$ in $\mathrm{O} 2$ with a flow rate of 1-1.5 L/min for induction, and anesthesia was maintained during tests with $2.5 \%$ isoflurane. Body temperature was maintained at $37^{\circ} \mathrm{C}$ by a heating lamp throughout the testing procedure. After all measurements were completed, the decapitation method was applied under anesthesia by using a guillotine. The experiment was completed with the same number of animals as were present in the beginning of the experiment.

In experiment 1 , baseline PPI measurements were followed by baseline DPOAE and ABR tests. One week after the initial tests, on the test day, a single dose of saline (1 $\mathrm{mL} / \mathrm{kg}$ ) was administered intraperitoneally to the control group, and the experimental group received a single intraperitoneal dose of $160 \mathrm{mg} / \mathrm{kg}$ agmatine; the same measurements were repeated.

In experiment 2, baseline PPI measurements were followed by baseline DPOAE and ABR tests. $1 \mathrm{~mL} / \mathrm{kg}$ of saline was administered intraperitoneally to the control group, and 160 $\mathrm{mg} / \mathrm{kg}$ agmatine was administered to the experimental group for seven consecutive days. PPI measurements, DPOAE, and ABR tests were performed on the 7th day after drug administration.

\section{Statistical Analysis}

The statistical analyses of the obtained data were performed using the IBM SPSS Statistics for Windows, Version 20.0.
(Armonk, NY: IBM Corp.) program. The Shapiro-Wilk test, Q-Q, and histogram graphs were used to determine the normality of the data. Mean \pm standard deviation values were used. In-group DPOAEs and ABR responses of the control and experimental groups were compared with the Wilcoxon test results. The comparison of DPOAE and ABRs of the control and experimental groups was performed by the Mann-Whitney U test. PPI data of the control and experimental groups were compared with Student's t-test. $\mathrm{P}<0.05$ was considered statistically significant.

\section{Results}

\section{Experiment 1 (Acute treatments)}

The DPOAE results and $p$ values are summarized in Table 1. DPOAE responses were tested at frequencies of 2, 3, 4, 6 , and $8 \mathrm{kHz}$ at the baseline and after drug administration. There were no statistically significant differences in the baseline SNR values between groups $(\mathrm{P}>0.05)$. SNR values obtained after drug exposure in the agmatine group were not statistically significant at all frequencies compared with the baseline values $(\mathrm{P}>0.05)$. There were no statistically significant differences between the SNR values of the rats that were administered agmatine and the control group at any frequency $(\mathrm{p}>0.05)$.

The ABR results and $\mathrm{p}$ values are summarized in Table 2 . There were no statistically significant differences in the baseline ABR threshold values among the groups $(\mathrm{P}>$ 0.05). The initial ABR threshold values and values obtained in the agmatine group after drug exposure were similar ( $\mathrm{p}>$ 0.05). There was no significant difference between the ABR threshold of the rats treated with agmatine or those treated with saline $(\mathrm{P}>0.05)$ (Table 2).

Acute agmatine $(160 \mathrm{mg} / \mathrm{kg})$ treatment produced some significant disruptions in PPI at prepulse intensities of 74, 78 and $86 \mathrm{~dB}(\mathrm{p}<0.001, \mathrm{p}=0,003$, and $\mathrm{p}=0.015$, respectively) (Figure 1A). The treatment did not produce a significant change in the startle amplitude intensity compared to the control group ( $\mathrm{p}=0.38$ ) (Figure 1B).

\section{Experiment 2 (Chronic treatments)}

Comparisons of pre- and posttreatment DPOAE responses and $\mathrm{p}$ values are summarized in Table 3. There were no statistically significant differences in the baseline SNR values among the groups $(p>0.05)$. In neither of the frequencies, SNR values in the DPOAE results at the baseline and after 7 days of being treated with saline were not found to be significantly different in the control group ( $>>0.05)$ (Table 3).

Comparing the test results on the seventh day with those of the baseline revealed a statistically significant decrease in SNR values at all frequencies in the agmatine group $(p<0.05)$. When the control group was compared with the agmatine group, the SNR values of the agmatine group on the seventh day were significantly lower than those of the control group at all frequencies. $(\mathrm{p}<0.05)$ (Table 3$)$.

The ABR results before and after drug treatments and $p$ values are summarized in Table 4. The mean ABR thresholds were similar among the control and agmatine groups based on ABR tests performed at the baseline ( $>0.05)$ (Table 4). There were no significant differences 
between the initial ABR threshold values of the control group and values obtained after saline treatment $(p>0.05)$.
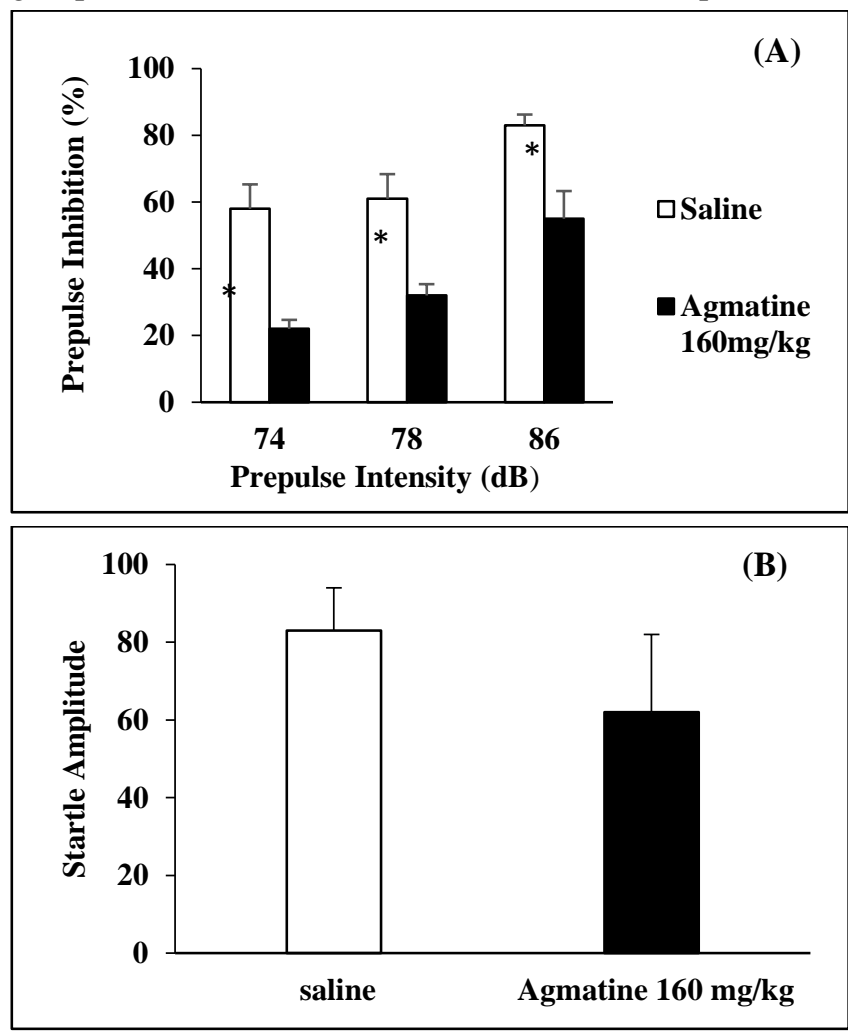

Figure 1. Effects of a single dose (acute) agmatine on prepulse inhibition (A) and the startle reflex (B) of rats $(* \mathrm{P}<0.05$, **P $<$ 0.01 Student's t-test; $\mathrm{n}=8$ for each group).
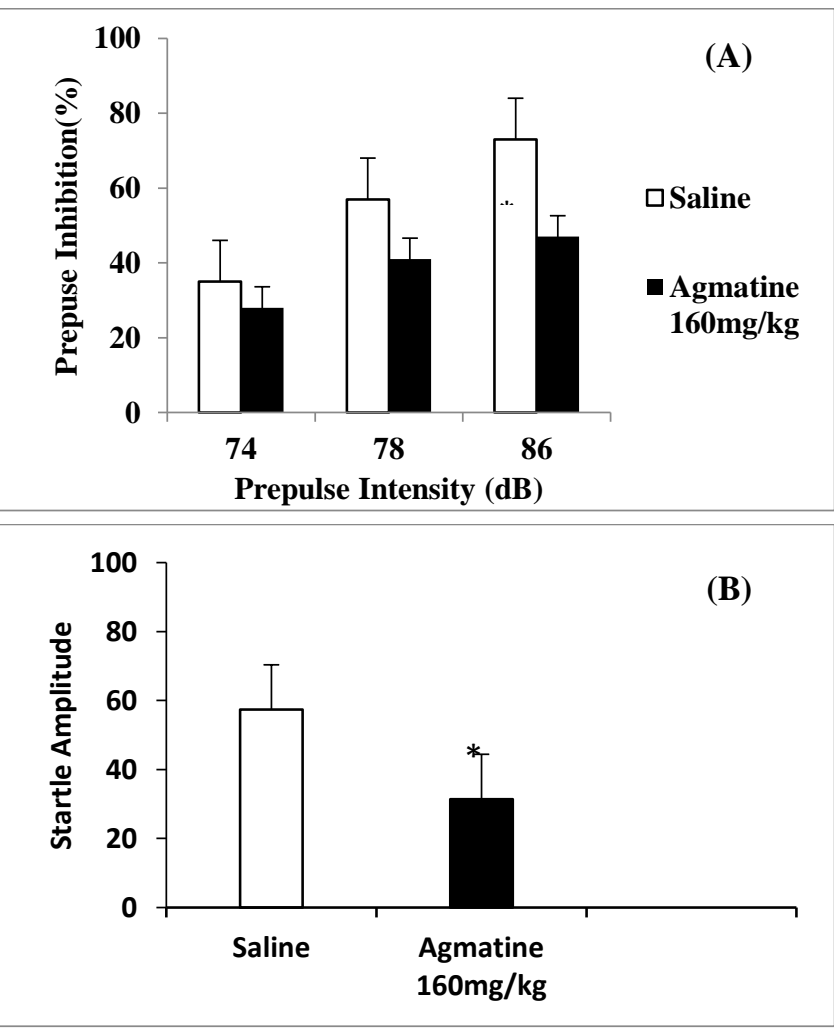

Figure 2. Effects of chronic agmatine on prepulse inhibition (A) and the startle reflex (B) of rats $\left({ }^{*} p<0,05^{*}\right.$ Student's t-test; $n=8$ for each group).

In the agmatine group, the ABR thresholds were significantly higher than the baseline values on the seventh day of the study $(\mathrm{p}<0.001)$. A comparison of the control group and agmatine group on the seventh day of the study indicated a significant increase in the mean hearing threshold in the agmatine group $(\mathrm{p}<0.05)$ (Table 4).

Chronic agmatine $(160 \mathrm{mg} / \mathrm{kg})$ treatment significantly disrupted PPI at a prepulse intensity of $86 \mathrm{~dB}(\mathrm{p}=0.009)$. The treatment also reduced PPI levels at intensities of 74 and $78 \mathrm{~dB}$ without reaching statistically significant levels (Figure 2A). In contrast to acute treatment, chronic treatment with agmatine caused a significant reduction in the baseline startle amplitude at $86 \mathrm{~dB}(\mathrm{P}=0.008)$ (Figure 2B).

\section{Discussion}

Our In the present study, the effects of agmatine, a polyamine neuromodulator, were tested for the first time via DPOAEs and ABRs in rats. While a single dose of agmatine did not produce any significant effect on DPOAEs or ABRs, chronic treatment for 7 days produced some significant impairments in DPOAEs and ABRs in rats. These results clearly suggest that agmatine may cause some auditory problems during chronic use.

We selected the agmatine dose according to our previous study. We observed significant disruption of PPI in rats by acute treatment with agmatine at a dose of $160 \mathrm{mg} / \mathrm{kg} 2$. Our findings indicating agmatine-induced disruptions in the PPI of the acoustic startle reflex also confirm and support the results of this study.

In the present study, agmatine disrupted PPI during both acute and chronic treatments. Because PPI disruption is an indicator for psychoses such as schizophrenia ${ }^{3,4}$, our results also suggested that there may be a link between agmatine, auditory impairments and schizophrenia. This suggestion has also been supported by the results of previous studies. In a previous study, we observed that agmatine at a dose of $160 \mathrm{mg} / \mathrm{kg}$ disrupted PPIs such as apomorphine in rats. ${ }^{2}$ In addition, we found significant increases in plasma agmatine levels in patients with schizophrenia. ${ }^{5}$ In this study, regression analysis indicated positive correlations between increased agmatine levels and the duration of the disease. ${ }^{5}$ Furthermore, in a postmortem study, Liu et al. showed increased agmatine concentrations in the frontal cortex of schizophrenia patients. ${ }^{6}$

Several molecular, cellular, neurophysiological, and neuroanatomical factors play roles in the pathophysiology of schizophrenia. The role of various neurotransmitter systems, especially dopaminergic, serotonergic and glutamatergic systems, and some biomarkers and genes in schizophrenia have been investigated. ${ }^{19,20}$ The critical role of polyamines such as spermidine and spermine in the regulation of cell membrane function and cerebral dopamine secretion suggests that they may also act in the pathogenesis of schizophrenia. ${ }^{21,22}$ NMDA receptor antagonists such as phencyclidine and ketamine can precipitate some psychotic symptoms in both experimental animals and humans, and it has been suggested that glutamatergic hypofunction is associated with psychotic symptoms. ${ }^{19,23,24}$ It has been shown that a polyamine agmatine also has a marked inhibitory effect on NMDA receptors in the rat hippocampus. ${ }^{25}$ Thus, it may have a role in the pathophysiology of schizophrenia. 
Table 1. Comparison of pre- and post-treatment on DPOAE responses

\begin{tabular}{|c|c|c|c|c|c|c|c|c|}
\hline & \multicolumn{2}{|c|}{ Saline } & \multicolumn{4}{|c|}{ Agmatine (160 mg/kg) } & \multirow[b]{2}{*}{ P3 } & \multirow[b]{2}{*}{ P4 } \\
\hline & Before & After & P1 & Before & After & P2 & & \\
\hline $2 \mathrm{kHz}$ & $13,75 \pm 3,29$ & $14,31 \pm 3,16$ & 0,836 & $14,60 \pm 2,28$ & $13,96 \pm 2,94$ & 0,393 & 0,13 & 0,57 \\
\hline $3 \mathrm{kHz}$ & $23,13 \pm 2,85$ & $23,19 \pm 3,03$ & 0,861 & $22,39 \pm 3,61$ & $21,90 \pm 4,08$ & 0,142 & 0,48 & 0,25 \\
\hline $4 \mathrm{kHz}$ & $26,35 \pm 1,70$ & $25,78 \pm 1,54$ & 0,256 & $25,52 \pm 1,58$ & $25,03 \pm 1,35$ & 0,306 & 0,08 & 0,97 \\
\hline $6 \mathrm{kHz}$ & $30,35 \pm 4,20$ & $29,78 \pm 4,87$ & 0,162 & $29,31 \pm 4,60$ & $29,05 \pm 4,60$ & 0,073 & 0,59 & 1,0 \\
\hline $8 \mathrm{kHz}$ & $35,70 \pm 2,81$ & $35,0 \pm 3,12$ & 0,108 & $34,54 \pm 3,67$ & $34,47 \pm 4,33$ & 0,753 & 0,59 & 0,89 \\
\hline
\end{tabular}

Values are presented as mean \pm standard deviation (SD); DPOAE: Distortion product otoacoustic emission; P1 control group baseline vs. after saline treatment (Wilcoxon Signed Ranks Test p>0.05); P2 agmatine group baseline vs. after agmatine treatment (Wilcoxon Signed Ranks Test p>0.05); P3 control group vs. agmatine group baseline (Mann Whitney U Test p>0.05); P4 Comparison of single dose saline and single dose agmatine administration (Mann Whitney U Test $\mathrm{p}>0.05$ ).

Table 2. ABR thresholds before and after application of drugs.

\begin{tabular}{|c|c|c|c|c|c|c|c|c|}
\hline & \multicolumn{2}{|c|}{ Saline } & \multicolumn{4}{|c|}{ Agmatine(160mg/kg) } & \multirow[b]{2}{*}{ P3 } & \multirow[b]{2}{*}{ P4 } \\
\hline & Before & After & P1 & Before & After & $\mathbf{P 2}$ & & \\
\hline \#ABR & $11,56 \pm 3,52$ & $12,18 \pm 3,63$ & 0,157 & $12,5 \pm 4,08$ & $13,75 \pm 5,0$ & 0,330 & 0,44 & 0,44 \\
\hline
\end{tabular}

Values are presented as mean \pm standard deviation (SD); \#ABR: Auditory brainstem response; P1 control group baseline vs. after saline treatment (Wilcoxon Signed Ranks Test p>0.05); P2 agmatine group baseline vs. after agmatine treatment (Wilcoxon Signed Ranks Test $\mathrm{p}>0.05$ ); P3 control group vs. agmatine group baseline (Mann Whitney U Test p>0.05); P4 Comparison of single dose saline and single dose agmatine administration (Mann Whitney U Test $\mathrm{p}>0.05$ ).

Table 3. Comparison of pretreatment and post-treatment DPOAE responses

\begin{tabular}{cccccccrcr}
\hline & \multicolumn{2}{c}{ Saline } & \multicolumn{7}{c}{ Agmatine (160mg/kg) } \\
\cline { 2 - 10 } & $\begin{array}{c}\text { Before } \\
\text { Mean } \pm \text { SD }\end{array}$ & $\begin{array}{c}\text { After } \\
\text { Mean } \pm \text { SD }\end{array}$ & $\mathbf{P}^{\mathbf{1}}$ & $\begin{array}{c}\text { Before } \\
\text { Mean } \pm \text { SD }\end{array}$ & $\begin{array}{c}\text { After } \\
\text { Mean } \pm \text { SD }\end{array}$ & $\mathbf{P}^{\mathbf{2}}$ & $\mathbf{P}^{\mathbf{3}}$ & $\mathbf{P}^{\mathbf{4}}$ \\
\hline $2 \mathrm{kHz}$ & $13,52 \pm 2,20$ & $14,23 \pm 2,16$ & 0,81 & $13,55 \pm 3,11$ & $8,9 \pm 3,37$ & $0,006^{* *}$ & 0,86 & $0,00^{* *}$ \\
\hline $3 \mathrm{kHz}$ & $24,80 \pm 3,09$ & $24,83 \pm 3,66$ & 0,87 & $23,22 \pm 3,42$ & $18,58 \pm 2,72$ & $0,002^{* *}$ & 0,16 & $0,00^{* *}$ \\
\hline $4 \mathrm{kHz}$ & $26,48 \pm 2,19$ & $27,13 \pm 3,06$ & 0,27 & $26,51 \pm 2,13$ & $18,54 \pm 2,48$ & $0,00^{* *}$ & 0,91 & $0,00^{* *}$ \\
\hline $6 \mathrm{kHz}$ & $31,33 \pm 3,19$ & $31,22 \pm 2,73$ & 0,87 & $29,95 \pm 3,59$ & $24,01 \pm 2,68$ & $0,001^{* *}$ & 0,31 & $0,00^{* *}$ \\
\hline $8 \mathrm{kHz}$ & $34,91 \pm 1,11$ & $34,53 \pm 1,28$ & 0,69 & $34,58 \pm 3,19$ & $19,8 \pm 3,34$ & $0,00^{* *}$ & 0,98 & $0,00^{* *}$ \\
\hline
\end{tabular}

Values are presented as mean \pm standard deviation (SD); DPOAE: distortion product otoacoustic emission; P1 control group baseline vs. after saline treatment (Wilcoxon Signed Ranks Test p>0.05); P2 agmatine group baseline vs. after agmatine treatment (Wilcoxon Signed Ranks Test $\mathrm{p} \leq 0.01^{* *}$ ); P3 control group vs. agmatine group baseline (Mann Whitney U Testi $\mathrm{p}>0.05$ ); P4 comparison of seven-day saline and seven-day agmatine administration (Mann Whitney $U$ Test $\mathrm{p} \leq 0.01 * *)$.

Table 4. ABR thresholds before and after drug treatments

\begin{tabular}{ccccccccc}
\hline \multicolumn{2}{c}{ Saline } & \multicolumn{7}{c}{ Agmatine (160mg/kg) } \\
\hline & $\begin{array}{c}\text { Before } \\
\text { Mean } \pm \text { SD }\end{array}$ & $\begin{array}{c}\text { After } \\
\text { Mean } \pm \text { SD }\end{array}$ & $\mathbf{P}^{\mathbf{1}}$ & $\begin{array}{c}\text { Before } \\
\text { Mean } \pm \text { SD }\end{array}$ & $\begin{array}{c}\text { After } \\
\text { Mean } \pm \text { SD }\end{array}$ & $\mathbf{P}^{2}$ & $\mathbf{P}^{\mathbf{3}}$ & $\mathbf{P}^{\mathbf{4}}$ \\
\hline${ }^{\#}$ ABR & $13,12 \pm 4,42$ & $12,50 \pm 4,08$ & 0,59 & $15,01 \pm 5,16$ & $19,06 \pm 4,17$ & $0,009^{* *}$ & 0,30 & $0,00^{* *}$ \\
\hline
\end{tabular}

Values are presented as mean \pm standard deviation (SD); \#ABR: Auditory brainstem response; P1 control group baseline vs. after saline treatment (Wilcoxon Signed Ranks Test p>0.05); P2 agmatine group baseline vs. after agmatine treatment (Wilcoxon Signed Ranks Test p>0.05); P3 control group vs. agmatine group baseline (Mann Whitney U Test p>0.05); P4 Comparison of single dose saline and single dose agmatine administration (Mann Whitney U Test $\mathrm{p}>0.05$ ).

Although the presence of ornithine decarboxylase, which is essential for the synthesis of spermin, spermidine, putrescine, and polyamines, has been shown in the mammalian cochlea, ${ }^{26,27}$ there has been no evidence regarding the role of agmatine in acoustic functions. As a significant molecule of the polyamine pathway, we hypothesized that agmatine could have an impact on cochlear function. Thus, we observed that chronic but not acute administration of agmatine leads to a disruption in DPOAE values and to an increase in the ABRthreshold. We consider that the impact of agmatine on cochlear function is driven by similar pathways reported for other polyamines. Type 1 primary afferent neurons located in the spiral ganglion of the cochlea have glutaminergic synapses and non-NMDA and NMDA receptors. ${ }^{28}$ Both non-NMDA and NMDA glutamate receptors are components of primary afferent neurons and play roles in neurotransmission in the primary auditory system. ${ }^{29}$ There is a region on the NMDA receptor complex specific to polyamines; therefore, polyamines can positively and negatively modulate NMDA-type glutamate receptor. ${ }^{30}$ Agmatine has been shown to selectively modulate the NMDA subclass of glutamate receptor channels in rat hippocampal neurons. ${ }^{25}$ Hence, we suggest that agmatine can modulate cochlear neurotransmission similar to other polyamines. Moreover, spermin and spermidine, which are degradation products of agmatine, may also activate NMDA receptors or excitotoxic damage to cochlear hairy cells, as observed in aminoglycoside-induced ototoxicity ${ }^{31}$ Agmatine may also have deteriorated cochlear physiology through the inhibition of nitric oxide synthase (NOS) and influencing NO levels, which regulate cochlear blood supply, neurotransmission, and cochlear endolymph homeostasis. ${ }^{32}$ In addition, the reduction of NO may also have deactivated potassium channels, which have been shown to modulate neural excitability in agmatine-administered rats. ${ }^{33}$

In this study, the disruption in DPOAE values and the increase in the ABR threshold following chronic doses of 
agmatine suggest that acoustic neurotransmission is affected by chronic agmatine administration and that the disruption in PPI and the reduction in the amplitude of the ASR may be directly associated with acoustic changes. The disruption of the PPI by the prestimuli that are $86 \mathrm{~dB}$ SPL above the background noise, in contrast to the prestimuli 74 and $78 \mathrm{~dB}$ above the background noise, may be associated with the increased hearing thresholds. Nevertheless, the disruption of the PPI may reflect a disruption in the sensorial gate-control mechanism. The reduction in the ASR amplitude may be a consequence of cochlear dysfunction caused by agmatine as well as central processing disorders, which has been previously shown in subjects with schizophrenia. ${ }^{34}$

Startle reactivity is defined as the magnitude of the startle response on either the initial stimulus presentation or over a relatively small number of startles trials. ${ }^{9}$ In schizophrenia patients with prodromal symptoms or in those experiencing their first episodes of schizophrenia, startle reactivity has been reported to be reduced along with the increase in the severity of the symptoms. ${ }^{35}$ Additionally, long-term followup studies of subjects with schizophrenia have demonstrated that PPI deficits more commonly develop in these patients compared to healthy controls, probably due to disease-related factors such as disease process, clinical state, or medication. ${ }^{36}$ The study of Hammer et al. revealed that although schizophrenia patients had PPI deficits compared to controls at the baseline, the PPI significantly increased in patients and decreased significantly in controls through the 6-year follow-up, and there were no significant differences regarding the PPI between the schizophrenia subjects and the controls at the end of the follow-up period. ${ }^{36}$ The blunted startle reactivity may be related to aging or to the change in hearing thresholds ${ }^{36}$ However, the presence of a blunted startle response in elderly subjects even after the application of stimuli adjusted to the hearing thresholds suggests that the reduction in startle reactivity is caused by the changes in central data processing instead of the change in primary auditory mechanisms. ${ }^{37}$

The cocktail party effect refers to the ability of people to focus on a single talker or conversation in a noisy environment, and cocktail party listening conditions include multiple perceptual-cognitive processes, such as listening conditions, target detection, and selective attention. ${ }^{38}$ It is known that the performance of patients with schizophrenia decreases under cocktail party conditions, which requires directing attention to the target speech under the conditions of multiple speakers. ${ }^{39}$ This may be the result of sensory stimulation-related hypersensitivity associated with a stimulus overload, ${ }^{14}$ which leads to cognitive fragmentation in patients with schizophrenia.

Polyamines are considered to play a critical role in vestibular function as well as acoustic function. ${ }^{40}$ Agmatine may directly affect cochlear physiology or indirectly affect cochlear physiology and pathology through the metabolism of polyamines. However, we have some limitations in the present study. Cochlear histological evaluation was lacking in this study. Therefore, we could not test whether changes in acoustic function were associated with any structural changes. We also could not investigate whether the acoustic dysfunction induced by agmatine was irreversible, akin to the ototoxicity induced by $\alpha$-difluoromethylornithine, which is an irreversible inhibitor of ornithine decarboxylase and polyamine synthesis. These results therefore need to be interpreted with caution.

\section{Conclusion}

Our results suggested that chronic agmatine exposure leads to significant negative changes in cochlear function. Our findings also imply that DPOAE and ABR tests should be considered in the diagnosis and follow-up of patients with psychoses, such as schizophrenia. Further studies investigating the role of agmatine in polyamine-induced ototoxicity and acoustic functions are required.

\section{Acknowledgement}

This work was supported by grants from Üsküdar University research foundation, İstanbul, Turkey. The language of the manuscript was corrected by American Journal Experts (AJE). We thank Mr. Emre Karaca for their technical assistance to the study.

\section{Conflict of Interest}

The authors declare that they have no conflict of interest.

\section{References}

1. Uzbay T. A new target for diagnosis and treatment of CNS disorders: Agmatinergic system. Curr Med Chem; 2012. 19:5116-5121. DOI: 10.2174/092986712803530601

2. Uzbay T, Kayir H, Goktalay G, Yildirim M. Agmatine disrupts prepulse inhibition of acoustic startle reflex in rats. J Psychopharmacol; 2010. 24:923-929.

DOI: $10.1177 / 0269881109102533$

3. Geyer MA, Krebs-Thomson K, Braff DL, Swerdlow NR. Pharmacological studies of prepulse inhibition models of sensorimotor gating deficits in schizophrenia: A decade in review. Psychopharmacology; 2001. 156:117-154.

DOI: $10.1007 / \mathrm{s} 002130100811$

4. Braff DL, Swerdlow NR, Geyer MA. Symptom correlates of prepulse inhibition deficits in male schizophrenic patients. Am J Psychiatry; 1999. 156:596-602. DOI: 10.1176/ajp.156.4.596

5. Uzbay T, Goktalay G, Kayir H, et al. Increased plasma agmatine levels in patients with schizophrenia. J Psychiatr Res; 2013. 47:1054-1060.

DOI: 10.1016/j.jpsychires.2013.04.004

6. Liu P, Jing Y, Collie ND, Dean B, Bilkey DK, Zhang H. Altered brain arginine metabolism in schizophrenia. Transl Psychiatry; 2016. 6:e871. DOI: 10.1038/tp.2016.144

7. Ramani D, De Bandt JP, Cynober L. Aliphatic polyamines in physiology and diseases. Clin Nutr; 2014. 33:14-22. DOI: 10.1016/j.clnu.2013.09.019

8. Fiori LM, Turecki GT. Implication of the polyamine system in mental disorders. J Psychiatry Neurosci; 2008. 33:102-110. Avalaible from: https://www.ncbi.nlm.nih.gov/pmc/articles/PMC2265 $312 /$ 
9. Geyer MA, Swerdlow NR. Measurement of startle response, prepulse inhibition, and habituation. CurrProtNeurosci; 2001. Chapter 8, Unit 8.7.

DOI: https://doi.org/ 10.1002/0471142301.ns0807s03.

10. Young JS, Fechter LD. Reflex inhibition procedures for animal audiometry: A technique for assessing ototoxicity. J Acoust Soc Am; 1983. 73:1686-1693.

11. Walter M, Tziridis K, Ahlf S, Schulze H. Context dependent auditory threshold determined by brainstem audiometry and prepulse inhibition in mongolian gerbils. Open J Acoust; 2012;2:34-49.

DOI: $10.4236 /$ oja.2012.21004

12. David A, Malmberg A, Lewis G, Brandt L, Allebeck P. Are there neurological and sensory risk factors for schizophrenia? Schizophr Res; 1995. 14:247-251. DOI: 10.1016/0920-9964(94)00068-j

13. Viertio S, Perala J, Saarni S, Koskinen S, Suvisaari J. Hearing loss in persons with psychotic disorder-findings from a population-based survey. Schizophr Res; 2014. 159: 309-311. DOI: 10.1016/j.schres.2014.08.016

14. Braff DL, Geyer MA. Sensorimotor gating and schizophrenia: Human and animal model studies. Arch Gen Psychiatry; 1990. 47:181-188.

DOI: 10.1001/archpsyc.1990.01810140081011

15. Abeloff MD, Rosen ST, Luk GD, Baylin SB, Zeltzman M, Sjoerdsma A. Phase II trials of alphadifluoromethylornithine, an inhibitor of polyamine synthesis, in advanced small cell lung cancer and colon cancer. Cancer TreatRep; 1986. 70:843-845. Avalaible from:

https://europepmc.org/article/med/3013400

16. Salzer SJ, Mattox DE, Brownell WE. Cochlear damage and increased threshold in alphadifluoromethylornithine (DFMO) treated guinea pigs. Hear Res; 1990. 46:101-112. DOI: https://doi.org/10.1016/0378-5955(90)90143-D

17. Nie L, Feng W, Diaz R, Gratton MA, Doyle KJ, Yamoah EN. Functional consequences of polyamine synthesis inhibition by L-alphadifluoromethylornithine (DFMO): Cellular mechanisms for DFMO-mediated ototoxicity. J Biol Chem; 2005. 280:15097-15102.

DOI: https://doi.org/10.1074/jbc.M409856200

18. Göktalay G, Kayir H, Ulusoy GK, Uzbay T. Social interaction of rats is related with baseline prepulse inhibition level. Neurosci Lett.; 2014. 582:125-129. DOI: https://doi.org/10.1074/jbc.M409856200

19. Lang UE, Puls I, Muller DJ, Strutz-Seebohm N, Gallinat J. Molecular mechanisms of schizophrenia. Cell PhysiolBiochem; 2007. 20:687-702.

DOI: $10.1159 / 000110430$

20. Hallak JE, de Paula AL, Chaves C, Bressan RA, Machado-de-Sousa JP. An Overview on the Search for Schizophrenia Biomarkers. CNS Neurol Disord Drug Targets; 2015. 14:996-1000.

21. Richardson-Andrews RC. A central role for the polyamines in the aetiology of schizophrenia. Med Hypotheses; 1983. 11:157-166.

DOI: https://doi.org/10.1016/0306-9877(83)90059-2

22. Ramchand CN, Das I, Gliddon A, Hirsch SR. Role of polyamines in the membrane pathology of schizophrenia. A study using fibroblasts from schizophrenic patients and normal controls. Schizophr Res; 1994. 13:249-253. DOI: 10.1016/09209964(94)90049-3

23. Tsai G, Coyle JT. Glutamatergic mechanisms in schizophrenia. Annu Rev Pharmacol Toxicol; 2002. 42:165-179.

DOI: 10.1146/annurev.pharmtox.42.082701.160735

24. Lindsley CW, Shipe WD, Wolkenberg SE, et al. Progress towards validating the NMDA receptor hypofunction hypothesis of schizophrenia. Curr Top Med Chem; 2006. 6:771-785.

DOI: $10.2174 / 156802606777057599$

25. Yang XC, Reis DJ. Agmatine selectively blocks the $\mathrm{N}$-methyl-D-aspartate subclass of glutamate receptor channels in rat hippocampal neurons. J Pharmacol Exp Ther; 1999. 288:544-549. Avalaible from: https://pubmed.ncbi.nlm.nih.gov/9918557/

26. Naguib MB, Hunter RE, Henley CM. Cochlear polyamines: Markers of otitis media-induced cochlear damage. Laryngoscope; 1994. 0104(8 Pt 1):10031007. DOI: 10.1288/00005537-199408000-00015

27. Brock M, Henley CM. Postnatal changes in cochlear polyamine metabolism in the rat. Hear Res; 1994. 72:37-43. DOI: 10.1016/0378-5955(94)90203-8

28. Puel JL. Chemical synaptic transmission in the cochlea. Prog Neurobiol; 1995. 47:449-476.

DOI: 10.1016/0301-0082(95)00028-3

29. Usami S, Matsubara A, Fujita S, Shinkawa H, Hayashi M. NMDA (NMDAR1) and AMPA-type (GluR2/3) receptor subunits are expressed in the inner ear. Neuroreport; 1995. 6:1161-1164.

30. Safieddine S, Eybalin M. Co-expression of NMDA and AMPA/kainate receptor mRNAs in cochlear neurones. Neuroreport; 1992. 3:1145-1148. DOI: 10.1097/00001756-199212000-00029

31. Basile AS, Huang JM, Xie C, Webster D, Berlin C, Skolnick P. N-methyl-D-aspartate antagonists limit aminoglycoside antibiotic-induced hearing loss. Nat Med; 1996. 2:1338-43. DOI: 10.1038/nm1296-1338

32. Brechtelsbauer PB, Nuttall AL, Miller JM. Basal nitric oxide production in regulation of cochlear blood flow. Hear Res.1994;77:38-42. DOI: 10.1016/03785955(94)90251-8

33. Budni J, Gadotti VM, Kaster MP, Santos AR, Rodrigues AL. Role of different types of potassium channels in the antidepressant-like effect of agmatine in the mouse forced swimming test. Eur J Pharmacol; 2007. 575:87-93. DOI: 10.1016/j.ejphar.2007.08.010

34. Kantrowitz JT, Epstein ML, Beggel O, et al. Neurophysiological mechanisms of cortical plasticity impairments in schizophrenia and modulation by the NMDA receptor agonist D-serine. Brain; 2016. 139(12):3281-3295. DOI: 10.1093/brain/aww262

35. Quednow BB, Frommann I, Berning J, Kuhn KU, Maier W, Wagner M. Impaired sensorimotor gating of the acoustic startle response in the prodrome of schizophrenia. Biol Psychiatry; 2008. 64:766-773. DOI: $10.1093 /$ brain/aww262

36. Hammer TB, Oranje B, Fagerlund B, Bro H, Glenthoj BY. Stability of prepulse inhibition and habituation of the startle reflex in schizophrenia: A 6-year follow-up study of initially antipsychotic-naive, first-episode 
schizophrenia patients. Int J Neuropsychopharmacol; 2011. 14:913-925.

DOI: $10.1017 / \mathrm{S} 1461145711000034$

37. Ludewig K, Ludewig S, Seitz A, Obrist M, Geyer MA, Vollenweider FX. The acoustic startle reflex and its modulation: Effects of age and gender in humans. Biol Psychol; 2003. 63:311-323. DOI: 10.1016/s03010511(03)00074-7

38. Li J, Wu C, Zheng Y, et al. Schizophrenia affects speech-induced functional connectivity of the superior temporal gyrus under cocktail-party listening conditions. Neuroscience; 2017. 359:248-257.
DOI: 10.1016/j.neuroscience.2017.06.043

39. Zheng $\mathrm{Y}, \mathrm{Wu} \mathrm{C}$, Li J, et al. Brain substrates of perceived spatial separation between speech sources under simulated reverberant listening conditions in schizophrenia. Psychol Med; 2016. 46:477-491. DOI: https://doi.org/10.1017/S0033291715001828

40. Henley C, Igarashi M. Polyamines in the lateral vestibular nuclei of the Squirrel Monkey and their potential role in vestibular compensation. Acta Otolaryngol; 1993. 113:235-238.

DOI: $10.3109 / 00016489309135799$ 